\title{
Preliminary Study: Glycemic Index of Brown and White Rice Variant IR64 in Healthy Adult Men
}

\author{
Nur Irika binti Idril, ${ }^{1}$ Aly Diana, ${ }^{2}$ Abdullah Firmansyah Wargahadibrata ${ }^{2}$ \\ ${ }^{1}$ Faculty of Medicine, Universitas Padjadjaran \\ 2Department of Medical Nutrition, Faculty of Medicine, Universitas Padjadjaran
}

Abstract
Objective: To measure the glycemic index of brown and white rice in healthy
adult men.
Methods: The study was conducted in April 2010 at Universitas Padjadjaran,
Jatinangor. Subjects of 21 healthy male students were randomly divided into 3
groups, which were given white bread (WB), white rice (WR) and brown rice (BR).
Results: The results show that the highest and lowest average values of the blood
glucose response was in the WR group at 30 minutes (126.9 mg/dL) and at 120
minutes (87.4 mg/dL), respectively. The glycemic index of brown rice (97.28) was
lower compared to the white rice (99.26).

\section{Introduction}

In most countries, especially in many developing countries, have undergone the dual burdens of disease. The prevalence of non-communicable and degenerative diseases has increased while the prevalence of communicable diseases is still high. ${ }^{1,2} \mathrm{~A}$ lot of studies indicated that most of the degenerative diseases are related to current lifestyle, especially the nutrition intake related to high glycemic index. ${ }^{3,4}$ This fact has urged other studies to find alternative food which provide less risk and can add benefits to health.

Since rice is the major source of carbohydrate in most Asian populations, including Indonesia, finding better alternative types of rice is essential. Many studies have explained the health benefits of brown rice (BR), including its advantages for diabetic patients. 5,6 Brown rice still has its bran layers, which make the BR an excellent source of magnesium, iron, selenium, manganese, vitamins B1, B2, B3 and B6, dietary fiber, and protein. ${ }^{5}$

\footnotetext{
Correspondence:

Aly Diana, Department of Medical Nutrition, Faculty of Medicine, Universitas Padjadjaran

Jl. Eijkman No. 38, Bandung 40161, Indonesia e-mail: diana.aly@gmail.com
}

The dietary fiber in bran layer traps nutrients, delaying their transit through gastrointestinal tract which leads to slower glucose absorption. As a result, the glycemic index of BR is lower than white rice (WR)..$^{5-7}$ Consequently, BR is considered as a healthier and safer substitute for WR. Nevertheless, the positive effect of BR (IR64 variant) which is locally produced and commonly consumed in Indonesia, on blood glucose level of the adult population is unknown. Therefore, this study aims to measure glycemic index of BR and WR after consumption in healthy adult men.

\section{Methods}

This study was an experimental study. Men, 1924 years old with normal body mass index (18.522.9), waist circumference of $\leq 90 \mathrm{~cm}$, no history of chronic disease, and were not on medication, were included as the subjects for the study. They also had normal fasting blood glucose level.

The study was conducted in April 2010. The number of subjects in this study was 21 men, picked randomly from the population of medical students in Universitas Padjadjaran. They were 
further divided into 3 groups. White bread (WB) group was the standard group, which was given 108 gram WB and water. The WR group was the control group, which was given 113 gram WR of IR64 variant and water. The BR group was the intervention group, which was given 123 gram BR of IR64 variant and water. The amount of the food given was different, but they all contained 50 gram of carbohydrate. Both WR and BR were recently cooked and the subjects had to finish the food within 10 minutes.

The independent variables included WR and $B R$, while the dependent variable was glycemic index. The BR glycemic index was lower (97.28) compared to that of WR (99.26) (Table 2). WR in this study was the IR64 variant which was polished until its color became white. Brown rice was the IR64 variant that was undergone several processes, including removal of the husk part. However, the bran layer is still intact because there was no polishing process performed. The glycemic index is the area under the blood glucose curve after consuming 50 gram of carbohydrate. The curve was calculated for each type of food by taking blood samples from participants at 0 minute (fasting blood glucose) and every 30 minutes after consumption for two hours. The analysis was conducted to compare the glycemic index of WR and BR by using the glycemic index of bread as the standard measurement. The

Table 1 Mean of Blood Glucose Response in WB, WR, and BR Groups

\begin{tabular}{|c|c|c|c|c|c|}
\hline \multirow{2}{*}{ Type of food } & \multirow{2}{*}{ Sample } & \multicolumn{4}{|c|}{ Time } \\
\hline & & $30 \mathrm{~min}$ & $60 \mathrm{~min}$ & $90 \mathrm{~min}$ & $120 \mathrm{~min}$ \\
\hline \multirow[t]{7}{*}{ WB } & 1 & 85 & 102 & 88 & 91 \\
\hline & 2 & 116 & 81 & 118 & 95 \\
\hline & 3 & 108 & 96 & 108 & 106 \\
\hline & 4 & 111 & 86 & 87 & 87 \\
\hline & 5 & 91 & 109 & 105 & 100 \\
\hline & 6 & 136 & 135 & 101 & 99 \\
\hline & 7 & 129 & 114 & 111 & 98 \\
\hline Mean $\pm S D$ & & $110.9 \pm 18.5$ & $103.3 \pm 18.3$ & $102.6 \pm 11.6$ & $96.6 \pm 6.2$ \\
\hline \multirow[t]{7}{*}{ WR } & 1 & 130 & 97 & 93 & 84 \\
\hline & 2 & 125 & 107 & 104 & 100 \\
\hline & 3 & 119 & 91 & 88 & 87 \\
\hline & 4 & 153 & 107 & 76 & 87 \\
\hline & 5 & 98 & 105 & 102 & 80 \\
\hline & 6 & 120 & 100 & 98 & 84 \\
\hline & 7 & 143 & 121 & 112 & 90 \\
\hline Mean $\pm S D$ & & $126.9 \pm 17.9$ & $104.0 \pm 6.4$ & $96.1 \pm 10.4$ & $87.4 \pm 6.9$ \\
\hline \multirow[t]{7}{*}{ BR } & 1 & 114 & 118 & 119 & 99 \\
\hline & 2 & 111 & 105 & 91 & 96 \\
\hline & 3 & 147 & 81 & 113 & 107 \\
\hline & 4 & 117 & 77 & 99 & 84 \\
\hline & 5 & 140 & 124 & 95 & 92 \\
\hline & 6 & 102 & 91 & 86 & 83 \\
\hline & 7 & 93 & 87 & 87 & 85 \\
\hline Mean+SD & & $117.7 \pm 19.5$ & $97.6 \pm 18.4$ & $98.6 \pm 12.8$ & $92.3 \pm 9.0$ \\
\hline
\end{tabular}

SD: Standard Deviation 
confounding factors, i.e. age, gender, BMI, and waist circumference were controlled through the inclusion criteria. Therefore, these factors were not taken into account in the analysis.

Table 2 Glycemic Index of Both BR and WR

\begin{tabular}{ccc}
\hline $\begin{array}{c}\text { Type of } \\
\text { food }\end{array}$ & $\begin{array}{c}\text { Increment area } \\
\text { under the curve } \\
\text { (IAUC) }\end{array}$ & $\begin{array}{c}\text { Glycemic index } \\
\text { (GI) }\end{array}$ \\
\hline WB & 9287.14 & 100.00 \\
WR & 9218.57 & 99.26 \\
BR & 9034.29 & 97.28 \\
\hline
\end{tabular}

\section{Results}

The lowest and highest average values of the blood glucose response were found in the WR group at 120 minutes $(87.4 \mathrm{mg} / \mathrm{dL})$ and at 30 minutes $(126.9 \mathrm{mg} / \mathrm{dL})$, respectively. There was no significant difference in mean and median of each group (Table 1). The glycemic index was then calculated using the trapezoidal method to measure the increment area under the curve (IAUC) and the formula below: ${ }^{8}$

Glycemic Index =

IAUC for blood glucose response for a type of food

Corresponding area after equicarbohydrate portion of reference food

\section{Discussion}

The blood glucose increment in BR group was lower than WR group in the first 30 minutes in this study. However, the blood glucose level in WR group seemed to decrease to a lower level compared to the blood glucose level in BR group. Blood glucose level in BR group was seen at a higher level, which was sustained until 120 minutes.

Various literatures consist of grey literatures and clinical studies ${ }^{7,9-11}$ suggest that BR has lower glycemic index and can be classified as food with

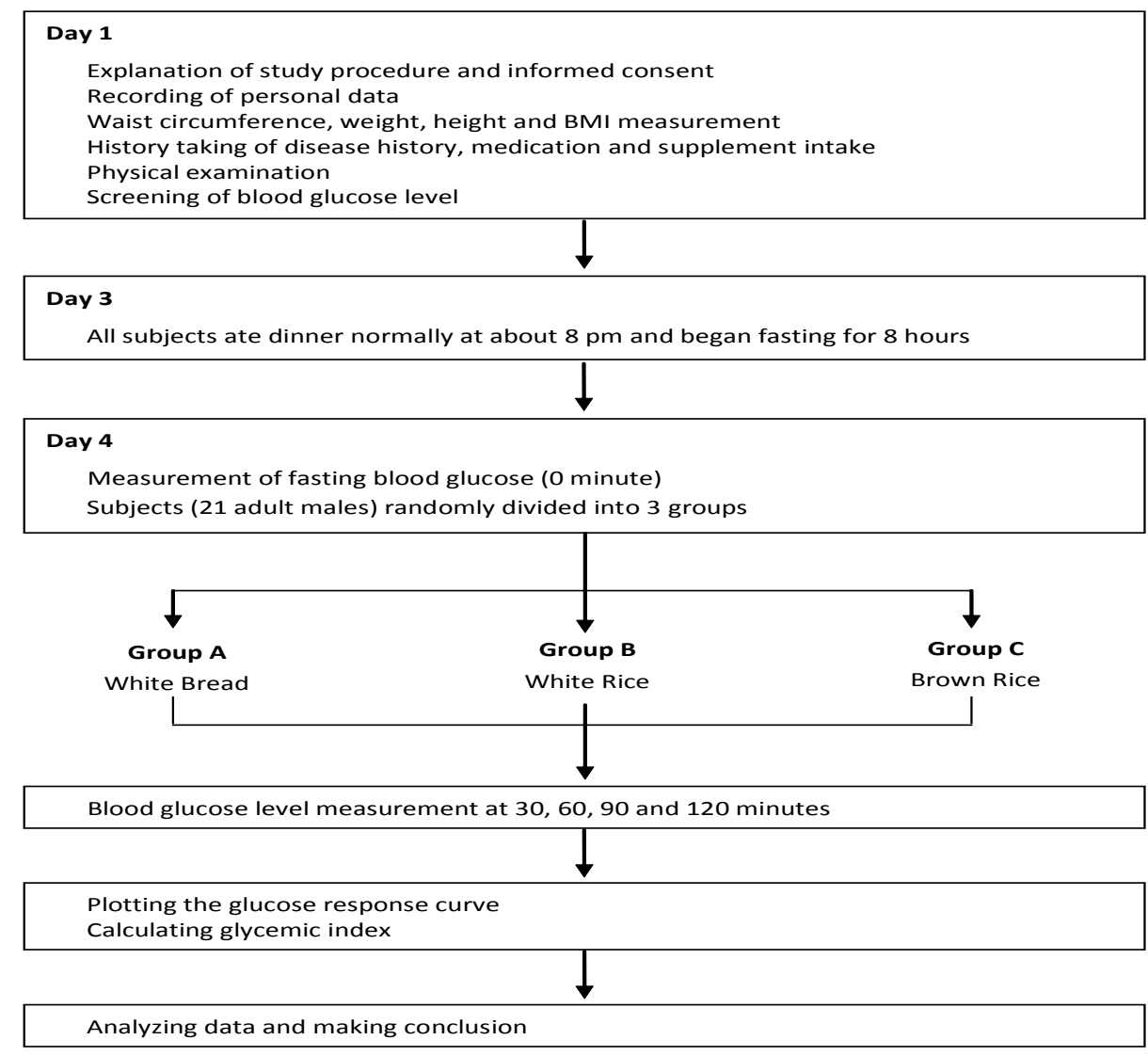

Fig. 1 Experimental Procedure Scheme 
moderate glycemic index (55-70). However, our experiment shows that although the glycemic index of $B R$ is lower than WR, both $B R$ and WR glycemic index is classified as high (70-100).

The study in Japan stated that the glycemic index of BR is 61.5, lower than the finding in this experiment. ${ }^{7}$ These different results may be related to the variant or species of rice used in the study. In the previous study in Japan, the type of BR tested was the short grain rice (Japonica) produced in Hokkaido, Japan. Meanwhile, the BR variant used in this study is IR64. The IR64 variant was used because it is considered the type of rice most commonly consumed in Indonesia.

The different variant may influence the starch content in the rice. Although it was not tested in this experiment, the IR64 BR might have a higher starch content compared to Japonica variant. The different variants may have different fiber content in the bran layer. The Japonica variant might have higher fiber content than the IR64 which making it more resistant to the $\alpha$-amylase activity and slowing down the absorption process in the intestine. The WR from Japonica variant has moderate glycemic index. ${ }^{11}$

The participant individual differences may also affect the glycemic index of the BR and WR. These differences may be due to the race or the rice consumption habit of the participants. ${ }^{12}$ Frequent rice consumption might have influenced the digestion or digestive enzymes by increasing the efficacy of the digestive enzymes. This leads to faster and more efficient carbohydrate absorption that triggers a higher blood glucose response. ${ }^{13}$

There are several limitations in this study. First, the study was only performed in 1 day whereas in a previous similar study, the measurement was performed after the participants consumed both BR and WR for several days. The second limitation is that the measurement of carbohydrate in the food given to all participants is done based on the food composition table (Daftar Komposisi Bahan Makanan, DKBM). ${ }^{14}$ DKBM is the standard food reference table in Indonesia. However, the DKBM values may not be accurate as food may vary depending on the method of production, the species or variant of rice, and other factors.

Despite the limitations, this study showed that rice variant and production method may impact the glycemic index. Therefore, this result also suggested the importance of local product evaluation. This is especially important for food products that are not only affected by geographic conditions (soil contains, environment factors) but also the variant and the processes from the production to consumption. ${ }^{13}$ An experimental study that addressed all of these contributing factors should be conducted before a decision to encourage or discourage promotion of $\mathrm{BR}$ as a better substitute for WR to public in Indonesia is made.

\section{References}

1. Popkin BM. Global nutrition dynamics: the world is shifting rapidly toward a diet linked with noncommunicable diseases. Am J Clin Nutr. 2006;84(2):289-98.

2. Doak CM, Adair LS, Bentley M, Monteiro C, Popkin BM. The dual burden household and the nutrition transition paradox. Int J Obes. 2005;29(1):129-36.

3. Augustin LS, Franceschi S, Jenkins DJ, Kendall CW, La Vecchia C. Glycemic index in chronic disease: a review. Eur J Clin Nutr. 2002;56(11):1049-71.

4. Jenkins DJ, Kendall CW, Augustin LS, Franceschi $S$, Hamidi M, Marchie A, et al. Glycemic index: overview of implications in health and disease. Am J Clin Nutr. 2002;76(1):266-73.

5. Babu PD, Subhasree RS, Bhakyaraj R, Vidhyalakshmi R. Brown rice - beyond the color reviving a lost health food - a review. AmericanEurasian J Agronomy. 2009;2(2):67-72.

6. Panlasigui LN, Thompson LU. Blood glucose

lowering effects of brown rice in normal and diabetic subjects. Int J Food Sci Nutr. 2006;57(34):151-8.

7. Ito $Y$, Mizukuchi $A$, Kise $M$, Aoto $H$, Yamamoto $\mathrm{S}$, Yoshihara $\mathrm{R}$, et al. Postprandial blood glucose and insulin responses to pre-germinated brown rice in healthy subjects. J Med Invest. 2005;52(34):159-64.

8. Sugiyama M, Tang AC, Wakaki $\mathrm{Y}$, Koyama W. Glycemic index of single and mixed meal foods among common Japanese foods with white rice as a reference food. Eur J Clin Nutr. 2003;57(6):74352.

9. The GI diet guide [database on the Internet]. 2011 [cited 2012 Jan 25]. Available from: http:// www.the-gi-diet.org/lowgifoods/.

10. Indrasaria SD, Purwanib EY, Wibowoa $P$, Jumalia. Glycemic Indices of some rice varieties. Indonesian J Agriculture. 2010;3(1):9-16.

11. Foster-Powell K, Holt SH, Brand-Miller JC. 
International table of glycemic index and glycemic load values: 2002. Am J Clin Nutr. 2002;76(1):556.

12. Egede LE, Mueller M, Echols CL, Gebregziabher M. Longitudinal differences in glycemic control by race/ethnicity among veterans with type 2 diabetes. Med Care. 2010;48(6):527-33.
13. Vosloo MC. Some factors affecting the digestion of glycaemic carbohydrates and the blood glucose response. J Family Ecol Consumer Sci. 2005;33:1-9.

14. Direktorat Gizi Departemen Kesehatan. Daftar komposisi bahan makanan. Jakarta: Bhratara Karya Aksara; 1981. 